\title{
La memoria en el diván
}

\author{
Fanny Blanck-Cereijido
}

La memoria constituye la trama subjetiva de la identidad, sostiene la imagen del sujeto a lo largo de su tiempo vital. Debemos tener una historia de nuestra vida, que ofrezca cierta continuidad, aunque esta historia sea en gran parte ficticia, contenga lagunas y errores. La memoria se manifiesta en recuerdos, pero también como acciones repetitivas que reproducen situaciones traumáticas de las que el sujeto no es consciente, conductas que están claramente más allá del principio de placer. La transferencia, que es la relación del analizante con su analista, es, entre otros elementos, una repetición nunca idéntica, de esquemas de relación y de conducta que provienen del pasado y que al aparecer en la situación de análisis, permiten su comprensión y modificación. La memoria no es un depósito inamovible de huellas mnémicas, ya que estas huellas siempre se reinscriben a posteriori, como consecuencia de nuevos acontecimientos, o de nuevas comprensiones, de modo que la memoria es un archivo en perpetua construcción a lo largo de la vida. La acción del psicoanálisis no consiste en una recuperación de las huellas mnémicas olvidadas, sino esencialmente en la creación de nuevas comprensiones y sentidos de la biografía, de un nuevo modo de concebir y eslabonar algunos acontecimientos de la propia vida, que permiten la creación de nuevos proyectos y abren la posibilidad de un nuevo destino.

Memory constitutes the identity's subjective weave; it holds the person's image together throughout his or her life. We must have a history of our life that provides certain continuity, even if a large part of that history is fiction and contains lapses and errors. Memory manifests itself through memories, but also through repetitive actions that reproduce the traumatic situations the person is not aware of - a behavior, which is clearly beyond the pleasure principle. Transference - the relationship between the analyst and the patient - is, among other things, a repetition of relationships and behavioral schemata from the past, never identical, through its appearance in the analysis, makes it possible to be understood and modified. Memory is not a static reservoir of mnemic traces, since they are all rewritten a posteriori, as a consequence of new events or insights, which make 
memory an archive under constant construction throughout the person's life. The psychoanalytic work is not the recovery of forgotten mnemic traces, but the creation of new insights and meanings in the person's biography. It is the production of a new way to conceive and link the events in one's own life, which will allow the development of new projects and will open the door for a new destiny. 
Fanny Blanck-Cereijido

Asociación Psicoanalítica Mexicana

\section{La memoria en el diván}

La memoria es nuestra posibilidad de disponer de imágenes, conocimientos y recuerdos que pertenecen al pasado. Estos conocimientos del pasado son los que en algún momento se fijaron, dejaron una huella y son evocables. Una huella de un conocimiento pasado es algo presente que se puede evocar. La memoria depende de dos condiciones: 1) la conservación de conocimientos pasados sustraídos de la percepción actual; 2) la posibilidad de evocar ese conocimiento y hacerlo actual, lo que tiene como resultado el recuerdo. Platón denominó a estos dos momentos conservación de la sensación y reminiscencia. Aristóteles formula el problema que resulta de la conservación de la representación como huella de un conocimiento del pasado. Plantea que si permanece en nosotros una impronta, ¿cómo puede la percepción de esa impronta ser memoria de alguna otra cosa, y no solo de sí? El que recuerda no ve más allá de esa impronta; entonces, ¿cómo puede recordar lo que no está presente? Aristóteles dice que la impronta en el alma es como un cuadro que puede ser considerado por sí o por el objeto que representa; el recuerdo es una especie de deducción, ya que el que recuerda deduce que ya ha percibido lo que recuerda, está en su búsqueda. Así aparece el carácter activo o deliberativo del recuerdo. 
La memoria es la trama sobre la que se asienta la psique, sobre la que se constituye; nos reconocemos a nosotros mismos como una entidad en una secuencia de cierta continuidad de cambios propios y ajenos a lo largo de nuestra vida; incluso el reconocimiento de un sujeto por otro implica aceptarlo como producto de una historia particular.

Llenamos con nuestra imaginación los periodos olvidados y nuestra memoria, que elusiva, fragmentaria, inexacta, da fe de nuestra existencia y la sustenta, es nuestra trama identitaria. Las huellas mnémicas aparecen en la mente, más o menos creíbles, según su vinculación con los deseos, su grado de aceptabilidad, su coherencia. El sujeto olvida hechos esenciales de su propia historia, recuerda en forma distorsionada, incluso "evoca" hechos que nunca ocurrieron.

\section{Huella mnémica, fantasía, recuerdo}

Los recuerdos están formados por las huellas de la memoria, modeladas por los deseos, los fantasmas, sobre una conjunción inconsciente entre vivencias y cosas oídas y vistas, de acuerdo con una necesidad de volverlos inasequibles. La formación de fantasmas acontece por combinación y desfiguración análogamente a la descomposición de un cuerpo químico que se combina con otro. La primera desfiguración es la falsificación del recuerdo por fragmentación, en la cual son descuidadas precisamente las relaciones de tiempo (el corregir en el tiempo parece depender, precisamente, de la actividad del sistema conciencia). Así, un fragmento de la escena vista es reunido en la fantasía con otro de la escena oída, mientras que el fragmento liberado entra en otra conexión. Con ello, un nexo originario se vuelve inhallable. ${ }^{1}$

\footnotetext{
${ }^{1}$ Freud 1976a.
} 
En caso de sufrimiento psíquico, de síntomas, éstos se deben a situaciones inmanejables, vividas como tales, causadas por traumas que vienen del exterior, o hechos percibidos como traumáticos por los requerimientos emocionales de ese sujeto. Son circunstancias que en último término aparecen como situaciones de desvalimiento. Si este sufrimiento se establece como enfermedad, se debe a circunstancias que no han podido ser pensadas, tramitadas, ni han entrado en asociación con otras ideas. En el análisis buscamos la escena inconsciente que da lugar al síntoma, a la neurosis; la tarea es develar, o inventar la otra escena, deconstruir los fantasmas. El trauma causante de enfermedad no es recordado porque no existe huella rememorable, o es reprimido porque la conciencia no lo puede aceptar, ya que entraría en contradicción con los preceptos morales del sujeto, con sus creencias, o sería causa de un sufrimiento insoportable por lo que puede evocar. La existencia de estas huellas inaccesibles da lugar a la frase "las histéricas sufren de reminiscencias", es decir de recuerdos que las enferman. A pesar de esto, desde 1896, año en que Freud dice: "Ya no creo en mi neurótica", sabemos que el recuerdo es tal por lo vivido y fantaseado alrededor de él, y por su realidad psíquica, y no estrictamente por hechos materiales que hayan ocurrido de ese modo. Las guerras, las desapariciones de individuos en la "guerra sucia" del Cono Sur, la Shoá, son situaciones traumáticas insoslayables y universales, aunque cada individuo las vivirá según sus recursos y características.

Así como afirmamos que la memoria, la historia de cada sujeto, es la trama identitaria en la que se asienta su vida, no poder olvidar nada impediría las funciones psíquicas. Recordemos a Funes el memorioso ${ }^{2}$ que no tenía lugar mental disponible por un exceso de memoria, y al melancólico que no puede olvidar a su objeto perdido y es inepto para proseguir su vida.

${ }^{2}$ Borges 1974. 
En la historia de la clínica psicoanalítica, al comienzo se pensó que la meta para la cura era la recuperación del recuerdo traumático reprimido; hoy diríamos que lo que buscamos es la construcción de un sentido distinto para la historia y que para conseguirlo el instrumento más valioso es la transferencia que pasó de ser considerada un obstáculo a ser vista como un instrumento privilegiado; la relación transferencial pone en presente las demandas de amor de la infancia, y de la organización subjetiva del individuo, es un lazo afectivo intenso, automático y hasta cierto punto independiente de todo contexto de realidad. La demanda de análisis implica de entrada una dimensión particular: el paciente se dirige a alguien al que supone poseedor de un saber. Afuera del marco del análisis el fenómeno transferencial es constante pero a diferencia de lo que pasa en un análisis los participantes poseen cada uno su propia transferencia a la que responden en sus conductas y actitudes. En cambio se espera que el analista, a través de su propio análisis, esté en condiciones de conocer los modos como se ubica en sus relaciones personales con los otros, y sea capaz de intervenir sin interferir en lo que sucede en el analizante, al registrar qué figuras representa para él. Esta discriminación mantenida por el analista, que no asume el rol que se le atribuye, permite al paciente analizar esa transferencia y moverse del lugar en el que está ubicado.

La aparición de la transferencia en el analizante está determinada por la existencia y la actitud del analista, porque se ofrece a escuchar. La forma en la que aparece la situación transferencial depende de ambos participantes, de sus características personales e históricas; por eso no es nunca una repetición absoluta del pasado. La transferencia, el amor por el analista, es por un lado lo que permite confiar al paciente, tener deseos de hablar, intentar descubrir y comprender, pero también puede ser el lugar de las resistencias más duras. Cuanto más grande es la resistencia a recordar más se impone la compulsión 
a la repetición, que el analista tratará de transformar en rememoración o en una comprensión diferente del hecho biográfico.

De modo que la inicial búsqueda detectivesca del recuerdo deja lugar a su reconstrucción histórica a través del análisis de la repetición. Esta repetición se reedita en la neurosis de transferencia con la persona del analista y los demás sectores de la vida del analizante. El análisis es aquí, ahora, conmigo, pero también la repetición con los personajes o las situaciones que se presten a esa apoyatura transferencial. Es decir que el sujeto ha creado un modo de vivir, de proceder, de relacionarse que incluye conductas que le son dañinas, destructivas e inútiles, o enfermedades o claudicaciones. Lo repetitivo, rígido, aparece en todas las áreas de la vida. Decimos recordar, pero lo más importante es pensar, comprender cómo se eslabonan los hechos, crear lazos de sentido, para que el modo de pensar la propia vida, y la prospectiva, pueda cambiar.

Recuerdo, transferencia

Los contenidos más significativos pueden no ser pasibles de recuerdo; entonces ya no nos encontramos con aquellas histéricas que se hacían rápidamente transparentes, que levantaban la represión merced al influjo freudiano y se curaban en la talking cure. Las repeticiones son las que se encuentran más allá del principio del placer, es decir que son repetidas a pesar de ser perjudiciales, de causar sufrimiento. Aparecen como productos de la pulsión de muerte, tendencia a la autoagresión, a la destructividad, que encontramos en las situaciones melancólicas, en las conductas traumáticas o en las manifestaciones de las neurosis de destino, que aparecen sobre huellas sin palabras ni historia, que no han logrado constituirse en un relato. Hoy son muy frecuentes los cuadros limítrofes, también llamados fronterizos, porque pueden oscilar entre la neurosis y 
la psicosis. En estas personas encontramos la mente invadida por lo negativo, el vacío, la nada, la falta de contenido y representaciones y actúan en lugar de recordar, dramatizan una historia que tratamos de convertir en un texto inteligible. Han padecido traumas que sólo pueden ser deducidos retroactivamente, como si lo inscrito fuese de índole tan destructiva que hubiera desgarrado el tejido psíquico, dejando una cicatriz que no se puede transformar en recuerdo ni memoria, sino que permanece activa como causa de sufrimiento. En sujetos afectados por estos procesos, el analista no encuentra el recuerdo preexistente, sino que colabora para crear contenidos nuevos, algo que explique, que dé forma, razón de lo sucedido. La presencia de alguien que escucha de una manera inédita abre un circuito, convierte una situación solipsista en un sistema abierto y el sujeto, sostenido en un vínculo de amor, intenta salidas de su universo repetitivo y estéril.

Hemos descrito algunas formas de la memoria: recuerdos, repeticiones compulsivas, la situación transferencial. La represión es el mecanismo de defensa existente en las neurosis que impide que una representación que ha tenido lugar en la conciencia y se ha hecho inconsciente sea conocida por el sujeto. Se trata de una huella mnémica recuperable en el análisis, que ha existido como representación y fue reprimida por inaceptable para la conciencia. Éstos son cuadros neuróticos en los que no es difícil rehacer la continuidad psíquica, al contrario de las situaciones en las afecciones traumáticas graves, en casos limítrofes o en las psicosis, aunque debemos matizar esta afirmación: los padeceres psíquicos rara vez son cuadros puros.

\section{Verdad, realidad histórica, historia, memoria}

La recuperación de la verdad material no es posible, pero el concepto de realidad histórica ofrece una tentativa de solución 
a este problema. Se trata de la historia forjada por el analizante, en su versión, de modo que la noción de los acontecimientos sucedidos es modelada por el efecto parcial y fragmentario de deseos y fantasías, dando origen a la propia verdad histórica.

Para que haya realidad psíquica, pensamiento y lenguaje, el sujeto tiene que haber pasado por una experiencia de pérdida, ya que la posibilidad de simbolización aparece a raíz del alejamiento del mítico objeto primario. Rompiendo con la idea de recuperación fidedigna de la historia, la huella mnémica primera se asienta sobre esa pérdida, excluyendo un aspecto del acontecer o del objeto, que ni siquiera ha podido ser inscrito. De manera que la verdad histórica de cada sujeto se apoya en el carácter de pérdida que tiene la creación de la realidad psíquica.

En ningún campo del conocimiento podemos concebir una realidad externa cognoscible independiente de quien la investigue. Lo que se conserva y es pasible de ser investigado, son restos arqueológicos y documentos que han sufrido una selección inevitable. El dato histórico aparece atravesado por la selección y la interpretación, y es así un dato construido.

Lo sabido a partir de la acción de la represión primaria anula la esperanza de un completo recordar

la reflexión de que aún en las psicosis más profundas el recuerdo inconsciente no se abre paso, de suerte que el secreto de las vivencias infantiles no se trasluce ni en el delirio más confundido. Y viendo así que lo inconsciente nunca supera la resistencia de lo consciente, se hunde también la expectativa de que en la cura se podría ir en sentido inverso, hasta el completo domeñamiento de lo inconsciente por lo consciente. ${ }^{3}$

Veamos ahora cómo pensar los procesos perceptivos que darán origen a la huella mnémica: ¿cómo se procesa lo interno, lo

${ }^{3}$ Freud 1976b. 
que proviene de las sensaciones corporales o del pensamiento frente a lo que impacta desde el exterior? ¿La alteridad percepción-alucinación es absoluta? Por un lado, nuestra teoría no concibe la percepción desde el punto de vista psicológico, puramente fenoménico y, por el otro, la representación alude al fantasma reprimido de una pulsión prohibida, y es heredera del deseo y de la alucinación. La inhibición de la alucinación da lugar a la representación y al pensamiento representativo. La figurabilidad, los recuerdos hiperintensos, las fantasías diurnas, son fenómenos muy cercanos a la alucinación.

De modo que el sujeto que percibe está afectado por el fracaso de la alucinación primaria, marcado de un modo particular por la pérdida de su objeto primordial. Lo percibido de un modo aparentemente inmediato es fruto de un proceso que parte del negativo de la pérdida del objeto de la satisfacción alucinatoria. ${ }^{4}$ La percepción, a pesar de ser concebida como externa, proviene de un trabajo psíquico: la constitución de las representaciones se torna posible en el encuentro con los elementos simbólicos que constituyen el lenguaje que designa lo percibido. Este lenguaje está marcado por el afecto que lo inviste y las asociaciones que evoca. ¿Hasta qué punto no será legítimo considerar a la representación una construcción?

Cuando la percepción despierta afectos insoportables la desmentida conduce a su abolición y el sujeto descree de lo que ven sus ojos. De modo que debemos separar el objeto de la percepción del juicio sobre su existencia, y cuestionar la neutralidad de la percepción. Esto llevó a Bleger a afirmar que la inmaculada percepción no existe, ya que depende de lo deseado y buscado en el campo perceptivo.

Las construcciones, que son hipótesis que el analista ofrece al analizante para llenar un hueco en los recuerdos de su vida, están creadas de modo análogo a las alucinaciones y los delirios:

${ }^{4}$ Botella y Botella 2003. 
el delirio, que consideramos patológico, también es una tentativa de recobrar, reconstruir, reinvestir representaciones que han sido desinvestidas al comienzo del proceso psicótico. En los delirios y las alucinaciones las experiencias que tuvieron lugar en una edad temprana, que fueron vividas y después abolidas internamente porque no eran representables o porque no podían ser elaboradas, vuelven a la mente como alucinaciones, como imágenes que corresponden a la realidad externa. Así como las construcciones producen su efecto intentando reconstruir un fragmento biográfico, los delirios deben la fuerza de su convicción a lo que tienen de experiencia histórica. Freud, en 1937, extendió esta concepción de la formación del delirio individual a la humanidad como un todo ya que consideró que ésta ha desarrollado delirios que son inaccesibles a la crítica lógica y que contradicen a la realidad. Si a pesar de esto son capaces de ejercer un poder extraordinario merecen la misma explicación que en los casos individuales: deben su poder al elemento de verdad histórica que han traído de la represión de un pasado primitivo y olvidado. Freud se refiere acá a las religiones, mitos y sagas históricas de la humanidad, que satisfacen la necesidad de protección e inmortalidad.

La construcción es también una deconstrucción, un desarmar el fantasma, que también es una construcción. El texto que el paciente produce no posee más verdad histórica que la construida, frente a la tentativa de constituir el presente, cuya concepción depende del retorno de lo reprimido. Freud cuida de delimitar la diferencia de los papeles entre el analizante y el analista, ya que este último — dice — no habiendo vivido ni reprimido nada de lo que habla el analizante, no debe intentar comprender, sino trabajar, como el inconsciente. Así, mientras uno procede buscando el sentido, el otro construye la novela familiar. Delirio entre dos, a condición de considerar que el delirio es el intento de restablecimiento, de reconstrucción de la enfermedad. ¿Qué es el núcleo de verdad del delirio, confundido 
con el trozo de verdad histórica denegado que da su eficacia a las construcciones delirantes? El origen es siempre ficticio, mítico y cada vez que se trata de demostrar la estructura de una historia de un fantasma aparece la construcción, que suple la ausencia de un real, la pérdida de un fragmento de realidad histórica. Éstas son las historias de vida, las biografías traídas al análisis que acompañan a los sujetos y que, al modo de creencias y mitos, constituyen un sostén a pesar de que deberán ser examinadas y con frecuencia caerán con el paso del tiempo. En realidad los relatos que traen los analizantes tienen siempre un contenido mítico que forma parte de la propia historia, de la saga familiar, que, como la historia oficial de las naciones, son mitos que han sido transmitidos por el lenguaje, a veces a través del nombre y que pueden fijar un destino. Pueblan el consultorio versiones personales del mito de Narciso, de Edipo, que a lo largo del trabajo analítico podrán dar paso a tramas menos omnipotentes, más libres, más esperanzadas y vitales. Este cambio de la visión de la propia existencia permite desasirse de una atadura a un destino dado y crear una prospectiva, un proyecto para el futuro, que también veremos aparecer en el curso del análisis.

Se nos plantea el problema de poder cuestionar creencias y certezas y movernos adentro de los límites de la verdad, falible y parcial. ¿Acaso el inconsciente responde sólo a la verdad? La construcción puede rozar al inconsciente, y provocar una respuesta metonímica, confirmación indirecta, o efectos parecidos a la alucinación. ${ }^{5}$

\section{Compulsión de repetición}

El analizante cree firmemente que la repetición proviene de circunstancias externas, y no depende de su actitud o actividad.

${ }^{5}$ Blanck-Cereijido y Orosco 2005. 
Esta falta de razón de los hechos traumáticos a los que se somete crea el sentimiento de estar pasivamente gobernado por una fuerza extraña, desconocida, que se suele designar como destino. Así, ubicamos con el nombre de destino los hechos cuya causa desconocemos, las determinaciones que no podemos explicar. El destino aparece como una trama sin significación, sin sentido explicativo. ${ }^{6}$

Resulta claro que la compulsión a repetir en la transferencia y en la vida los episodios traumáticos, se sitúa, en todos los sentidos, más allá del principio de placer, ya que no produce ningún beneficio, y sí en cambio mucho sufrimiento, de modo que el sujeto aparece sometido a una parte de él mismo o a algún otro que lo obliga a mortificarse. Mientras no descubra las características de esa fuerza no podrá liberarse de esa trama negativa.

La temporalidad de lo inconsciente no deja de ser presente, no desaparece, ni da lo pasado por pasado. Las motivaciones carecen de sentido y los hechos aparecen de modo caótico: no hay causas y efectos. Algunas veces la repetición, que nunca es idéntica, ya que las circunstancias y los personajes cambian, intenta corregir el episodio que ocasionó sufrimiento. El juego del niño puede repetir una situación dolorosa, en la que es abandonado, transformándola en su actividad lúdica en una escena en la que él es quien abandona, como sucede en el fort$d a$. Éste es un juego que se hizo famoso, en el que Freud comenta una actividad de su nieto que intenta elaborar la ausencia de su madre. De esta forma, la repetición no es dañina, sino que se vuelve positiva, al proponer otro desenlace. Éste es el rol del análisis, introducir una nueva posibilidad, y conseguir otra ubicación del sujeto, como sujeto activo del deseo propio.

La repetición y la memoria tienen una función constructiva e identificante del psiquismo, ya que van dibujando, definiendo

${ }^{6}$ Hornstein 2004. 
cómo reacciona ese sujeto, cuál es su modo personal de responder a las circunstancias de la vida.

De todo esto inferimos que el saber que se genera en un psicoanálisis no tenía existencia previa, no era ni un secreto, ni un recuerdo a develar sino que es producto de una actividad creativa, poyética. Lo determinante para la producción de una nueva historia y una nueva prospectiva es la posibilidad de pensar la vida creando articulaciones explicativas diferentes, y comprensiones históricas inéditas.

Una demora excesiva en el recordar, una delectación en la memoria, en los recuerdos del pasado, está asociada a la melancolía. ${ }^{7}$ Esta exclusiva mirada hacia el pasado aparece cuando no se construyen expectativas del futuro. Una memoria que enfatiza los recuerdos, predica la autocomplacencia o la posición de víctima del sujeto, que implícitamente acusa a las circunstancias o a los padres de su destino. Estas personas están muy apegadas a los beneficios secundarios de la enfermedad — ser mirados con compasión, eximidos de ciertos escenarios - como para resignarla. La posición melancólica afirma que lo perdido es lo único valioso y el sujeto en lugar de asumir una pérdida, se pierde él mismo, en una identificación total con su objeto ideal y perdido.

Las identificaciones alienantes con los padres son otra forma de memoria que perpetúa en cada uno los rasgos de los personajes importantes de la historia, aunque le sean perjudiciales. Algunas veces los sentimientos superyoicos de culpa impiden una vida distinta a la de los progenitores. Las desidentificaciones abren caminos para lograr el conocimiento de lo propio, $y$ la posibilidad de conseguirlo y ubicar al sujeto en su propia generación, independiente del destino de la generación anterior.

Los analistas obtenemos dos tipos de datos históricos: unos procedentes de la versión que el propio paciente aporta acerca

\footnotetext{
${ }^{7}$ Rabotnikof 2003.
} 
de su pasado, datos que se confirman o cambian de acuerdo con los aconteceres transferenciales y otros, los extraemos del análisis del discurso y del recorrido transferencial durante el proceso de la cura. De la primera serie de datos podremos construir algunas hipótesis sobre las causas a las que el propio paciente imputa su sufrimiento; se trata de una causalidad que apunta a una escena sin temporalidad, como corresponde al tiempo de la "historia mítica". Esta causalidad se habrá de confrontar con los conocimientos obtenidos en la relación analítica merced a las formaciones de compromiso: lapsus, sueños, análisis del relato y, sobre todo, de la dimensión transferencial. El recuerdo depende de elementos como la construcción de la temporalidad, su historización a través de la interpretación, pero sobre todo de nuevas comprensiones y ordenamientos. Algunas veces la creación de secuencias históricas es explícita y otras, proviene de la elaboración de los hechos transferenciales. El resultado de estos procesos permite cambios en la visión del sujeto sobre sí mismo, sobre su ánimo y su conducta.

Existe un periodo anterior en la historia relatada por el paciente, del que sólo quedan algunos recuerdos sueltos, o huellas corporales. Este periodo, en el que el yo no tenía lenguaje verbal, se apoya en los relatos maternos y familiares; la construcción de esta historia también integra el trabajo analítico como prehistoria de nuestro sujeto.

La necesidad de alguna coherencia histórica lleva al analizante a crear cierta continuidad, compensar de alguna manera los tramos ausentes, las pérdidas que dislocaron las huellas. Este modo de entender la causación de los recuerdos y los síntomas incluye la existencia de un tiempo anterior y el otorgamiento de sentido a partir de un momento de resignificación, que introduce un intervalo entre el acontecer de los hechos y su resignificación traumática. Durante ese intervalo se va desarrollando una difuminación, un poetizar que constituirá el 
fantasma. Ya no se trata entonces de vencer la represión y de encontrar un recuerdo perfecto, enterrado como tal en la memoria, en una concepción lineal del tiempo de la enfermedad.

En esta tarea siempre tendremos una versión interpretada $a$ posteriori del hecho que se relata. La elaboración analítica produce constantemente modificaciones en la historia. La teoría del nachträglich ${ }^{8}$ sugiere que el pasado se concibe de otra manera cuando un nuevo conocimiento lleva a una concepción y ubicación diferente del sujeto a un nuevo sentido de los hechos vitales del presente. Esto ilumina retroactivamente los hechos pretéritos, y enriquece el caudal de significaciones que puede tener un hecho, un recuerdo del pasado o la concepción de todo un aspecto de la vida del sujeto. De este modo el sujeto reinscribe constantemente su historia vital y la reinterpreta a la luz de los nuevos sentidos que puede ir elaborando. Esto nos indica que la memoria no es un depósito inmóvil de huellas mnémicas, sino que cada trayecto vital, cada conocimiento nuevo que obtiene sobre sí mismo va modificando el carácter de las huellas y su sentido constitutivo. Cada vivencia que arroja luz sobre el presente se proyecta hacia el pasado, y el presente se puede constituir como causa de un pasado diferente, que a su vez crea una diferente posibilidad de futuro.

La historia que descubrimos puede equipararse a un palimpsesto: una página imperfecta y oscura, mostrándose a través de la otra, también desgarrada, más afín a lo que debería haber sido la historia, según el deseo del paciente. El trabajo

${ }^{8}$ Nachträglichkeit (francés: Aprés-coup). Freud utiliza con cierta frecuencia el sustantivo Nachträglichkeit, generalmente traducido como "posterioridad", "efecto retardado" o "retroacción", como así también el adjetivo nachträglich, que significa "posteriormente" o "a posteriori". Es común el empleo combinado de nachträglich con otros términos, como por ejemplo nachträglich Gehorsam, "obediencia retrospectiva" u obediencia de efecto retardado.

En alemán, tales palabras pueden ser entendidas tanto en el sentido de un "efecto diferido" (una manifestación que ocurre más tarde) como en el sentido de un retorno al pasado (un agregado a posteriori).

Ambos sentidos están presentes en el uso freudiano de estos vocablos. 
de la construcción va en dirección opuesta al de la creación del fantasma y, en este sentido, es una deconstrucción de la historia ideal, que remite al sujeto a los deseos, las limitaciones, faltas, concepciones narcisistas que su mito particular ha tratado de encubrir. ${ }^{9}$

Como mencionamos más arriba, las construcciones son hipótesis que elabora el analista, y las ofrece como una historia posible de aconteceres olvidados. La referencia histórica o biográfica particulariza la existencia del analizante, confiere a su vida cierta continuidad temporal, le otorga una existencia en la diacronía histórica, en contraste con un uso reiterado y exclusivo de la interpretación transferencial en el aquí y el ahora, que puede resultar reduccionista, anónima. Así, el psicoanálisis no se ubica como una disciplina de la historia arqueológica o genética, ni del presente absoluto, ya que su objeto es el inconsciente intemporal.

Encontramos que la búsqueda de la verdad tropieza con dificultades tanto en los relatos personales como en los de hechos históricos. Ambos aparecen marcados por el presente desde el que son narrados y alguna circunstancia de este presente determina su aparición.

En cuanto a lo público, la memoria personal y la historia se enfrentan, desconfiando una de la otra. Sin embargo, los testimonios de la Shoá y de las dictaduras latinoamericanas han tenido un papel muy fuerte para pensar el siglo xx. En ese momento nadie, si excluimos a los responsables de los genocidios, podía pensar en poner en duda su veracidad. El carácter de denuncia, la explicitación de sufrimientos inconcebibles tomaban legalidad al asumir estado público, al ser compartidos con la comunidad. Más aún, los sobrevivientes sentían el deber de denunciar, de informar. El conocimiento público llena una necesidad de solidaridad y una posibilidad de duelo compartido.

${ }^{9}$ Blanck-Cereijido 1993. 
Frente a estos hechos se discute cuán objetivos, cuánta exactitud y veracidad pueden transmitir, ya que es el mismo testigoprotagonista el que relata su historia. Tanto Sarlo, ${ }^{10}$ De Man, ${ }^{11}$ como Ricoeur ${ }^{12}$ plantean que el enfoque academicista, el relato de un tercero informado, ofrece más posibilidades de verdad, ya que es difícil que un protagonista sea un buen testigo. Quedan planteados varios problemas, porque esta postura supone que el académico es un observador exacto, que contempla su fenómeno de estudio desde un punto de vista teórico puro, que sería lo mismo que decir que el sujeto de la ciencia está absolutamente centrado y es objetivo. Por otro lado, una desconfianza sistemática a la observación y al testimonio personales pueden llegar a tales absurdos como la negación de la Shoá. ${ }^{13}$

Actualmente una posición teórica llamada el giro subjetivo revindica al sujeto y sus motivos como protagonista de su historia; de aquí que las historias orales y los testimonios personales han vuelto a ser considerados convincentes.

De todos modos es indudable la acción del deseo en la elaboración de la historia. En este sentido podemos tomar como ejemplo el modo en que Freud encara el relato de la vida de Moisés, ya que éste contiene elementos de su propio deseo acerca de su origen y destino personal. De acuerdo con Freud, Moisés no es de estirpe judía, sino el hijo secreto de una noble familia egipcia, que elige a los judíos como depositarios de la religión monoteísta de Akenaton. Freud despoja a Abraham del papel paterno y se lo adjudica a Moisés, personaje con el que parece identificarse. Esta historia se asemeja a una versión de la novela familiar descrita en $1909 .{ }^{14}$ En dicha novela,

\footnotetext{
10 Sarlo 2005.

11 De Man 1984.

12 Ricoeur 2004.

13 Vidal-Naquet 1994.

14 Freud 1976c.
} 
el padre real es suplantado por un noble, y el hijo resulta ser de un linaje muy superior al de la familia que lo alberga. Esta vertiente nos remite al Freud que quiere fundar el propio linaje, como si dijera a su padre que, a pesar de haber sido el niño del que él opinaba "No llegará a nada", llegó a tanto que se convirtió en el primer Freud. ${ }^{15}$

El análisis también proporciona una dimensión de la vida como un devenir que tiene un final. Los adultos pasan a hacer proyectos que no se extienden al infinito, la caída de la omnipotencia impone un límite temporal, que también integra la historización. La historización propuesta por el análisis no aspira a reconstruir de manera absoluta la historia del sujeto sino tan sólo a ayudarlo a pensar hipótesis, nuevos enlaces, sentidos nuevos para dar alguna coherencia a un relato plagado de lagunas, debido a la existencia de denegaciones, represiones y fantasías narcisísticas. Esta versión es una creación nueva, trabajo creativo de ambos partícipes, una historización que, si el proceso estuvo bien, permite inventar otra existencia, a través de la simbolización y la sublimación.

El efecto cohesivo e identificante de la memoria es tan definitorio, que las afecciones que la destruyen, como ciertas demencias o la enfermedad de Alzheimer avanzada, tienen efectos devastadores, ya que al privar al sujeto de sus recuerdos de sí mismo o de los otros y del vínculo que lo une a ellos lo convierten en un ser anónimo sin presente ni pasado.

15 Blanck-Cereijido 1997. 


\section{REFERENCIAS}

AmÉRY, Jean, 2001. Revuelta y resignación. Acerca de envejecer, Madrid, Pre-Textos.

Blanck-CereiJido, Fanny, 1993. "Historia y construcciones", en $\mathrm{El}$ tiempo, el psicoanálisis y los tiempos, N. Braunstein (compilador), México, Coloquios de la Fundación, pp. 25-34.

—, 1997. "Sigmund Freud y el Viejo Testamento", en Espectros del psicoanálisis, volumen 1, México, La Tinta en el Diván, pp. 67-106.

- y Orosco, Beatriz, 2005. "La transferencia y sus destinos", trabajo presentado en el Congreso Abierto de la Asociación Psicoanalítica Mexicana.

Botella, César y Sara Botella, 2003. La figurabilidad psíquica, Buenos Aires, Amorrortu Editores.

Borges, Jorge Luis, 1974. "Funes el memorioso", Obras completas 1923-1972, Buenos Aires, Emecé, pp. 485-490.

De Man, Paul, 1984. "Autobiography as De-Facement", en Rethoric of Romanticism, New York, Columbia University Press, pp. 67-81.

Freud, Sigmund, 1976a. "Manuscrito M. Fragmentos de la correspondencia con Fliess" (1897), Obras completas, tomo I, Buenos Aires, Amorrortu Editores, pp. 292-295.

—, 1976b. "Manuscrito N. Fragmentos de la correspondencia con Fliess" (1897), Obras completas, tomo I, Buenos Aires, Amorrortu Editores, pp. 301-302.

—, 1976c. "La novela familiar de los neuróticos" (1909), Obras completas, tomo IX, Buenos Aires, Amorrortu Editores, pp. 213219.

—, 1976d. "Más allá del principio del placer" (1920), Obras completas, tomo XVIII, Buenos Aires, Amorrortu Editores, pp. 1-61.

—, 1976e. "Construcciones en el análisis" (1937), Obras completas, tomo XXIII, Buenos Aires, Amorrortu Editores, pp. 255-269. Hanns, Luiz Alberto, 2001. Diccionario de términos alemanes de Freud, Buenos Aires, Lohlé-Lumen.

Hornstein, Luis, 2004. Proyecto terapéutico, Buenos Aires, Paidós. LeVI, Primo, 1988. Entrevistas y conversaciones, Madrid, Península. 
RAвOtNiKof, Nora, 2003. "Política, memoria y melancolía", Fractal (revista trimestral) [en línea], núm. 29, pp. 83-89, <http:// www.fractal.com.mx/F29rabotnikof.html>. [Consulta: 25 de abril de 2007.]

Ricoeur, Paul, 2004. La memoria, la historia, el olvido, Buenos Aires, FCE.

SArlo, Beatriz, 2005. Tiempo pasado, Buenos Aires, Siglo XXI Editores.

Semprún, Jorge, 2001. Viviré con su nombre, morirá con el mío, Madrid, Tusquets Editores.

Vidal-Naquet, Pierre, 1992. Assassins of memory. New York, Columbia University Press. 